\title{
УПРАВЛЕНИЕ СИСТЕМОЙ МОНИТОРИНГА И ОЦЕНКИ КОМПЕТЕНЦИЙ
}

\author{
Орехова Елена Владимировна \\ Аспирант, ГАОУ ВО «Московский городской \\ педагогический университет (МГПУ)» \\ oelenav@mail.ru \\ Ромашкова Оксана Николаевна \\ Д.т.н., профессор, ФГБОУ ВО «Московский \\ государственный лингвистический университет» \\ ox-rom@yandex.ru \\ Аннотация. В статье приводится пример разработки подсистемы инфор- \\ мационной среды непрерывного образования. Сформулированы базовые \\ функциональные требования к единой образовательной информационной \\ среде открытого и непрерывного образования, приведены бизнес-процес- \\ сы отдельных функциональных блоков.
}

\section{MONITORING AND ASSESSMENT SYSTEM \\ E. Orekhova \\ O. Romashkova}

Summary. The article provides an example of the development of a subsystem of the information environment of continuing education. The basic functional requirements to a unified educational information environment of open and continuing education are formulated, business processes of individual functional blocks are given.

Keywords: distance learning, continuing education; informatization of education, information environment.
Ключевые слова: дистанционное обучение, непрерывное образование; информатизация образования, информационная среда. развитием технологий растут и потребности в соответствующих компетенциях, однако наблюдается тенденция, что подготовка кадров отстает от роста потребностей на рынке труда. В связи с этим возникает дефицит квалифицированных кадров. В динамично меняющихся условиях жизни даже фундаментального образования может быть недостаточно. Изменилась сама цель образования, связанная с необходимостью человека приспосабливаться к постоянно меняющимся экономическим и технологическим условиям. На протяжении нескольких последних лет «образование на всю жизнь» заменяется «образованием через всю жизнь». И одними из основополагающих принципов становятся умение и способность организовывать самообразование в непрерывном режиме.

Развитие системы непрерывного образования в наиболее развитых странах показало, что только образование на протяжении всей жизни, позволяет создать условия не только для самообразования и развития личности, но и получать профессиональную подготовку, соответствующую современным тенденциям.
Профессор, доктор технических наук А. П. Владиславлев в своих работах в качестве основных принципов непрерывного образования выделяет:

- принцип целенаправленности;

- принцип индивидуализированного обучения;

- принцип непрерывности, дающий человеку возможность выбирать траекторию получения образования;

- принцип системности, заключающийся в том, что реализация концепции непрерывного образования должна включать не просто совершенствование работы отдельных типов образовательных учреждений, увеличение количества этих типов и направлений их деятельности, а создание именно системы непрерывного образования, основой построения которой должен стать именно системный подход.

Система непрерывного образования направлена на реализацию следующих функций [1, 2]:

- обеспечение адаптации человека к постоянно меняющимся условиям не только профессиональной деятельности, но и социальной среды путем 


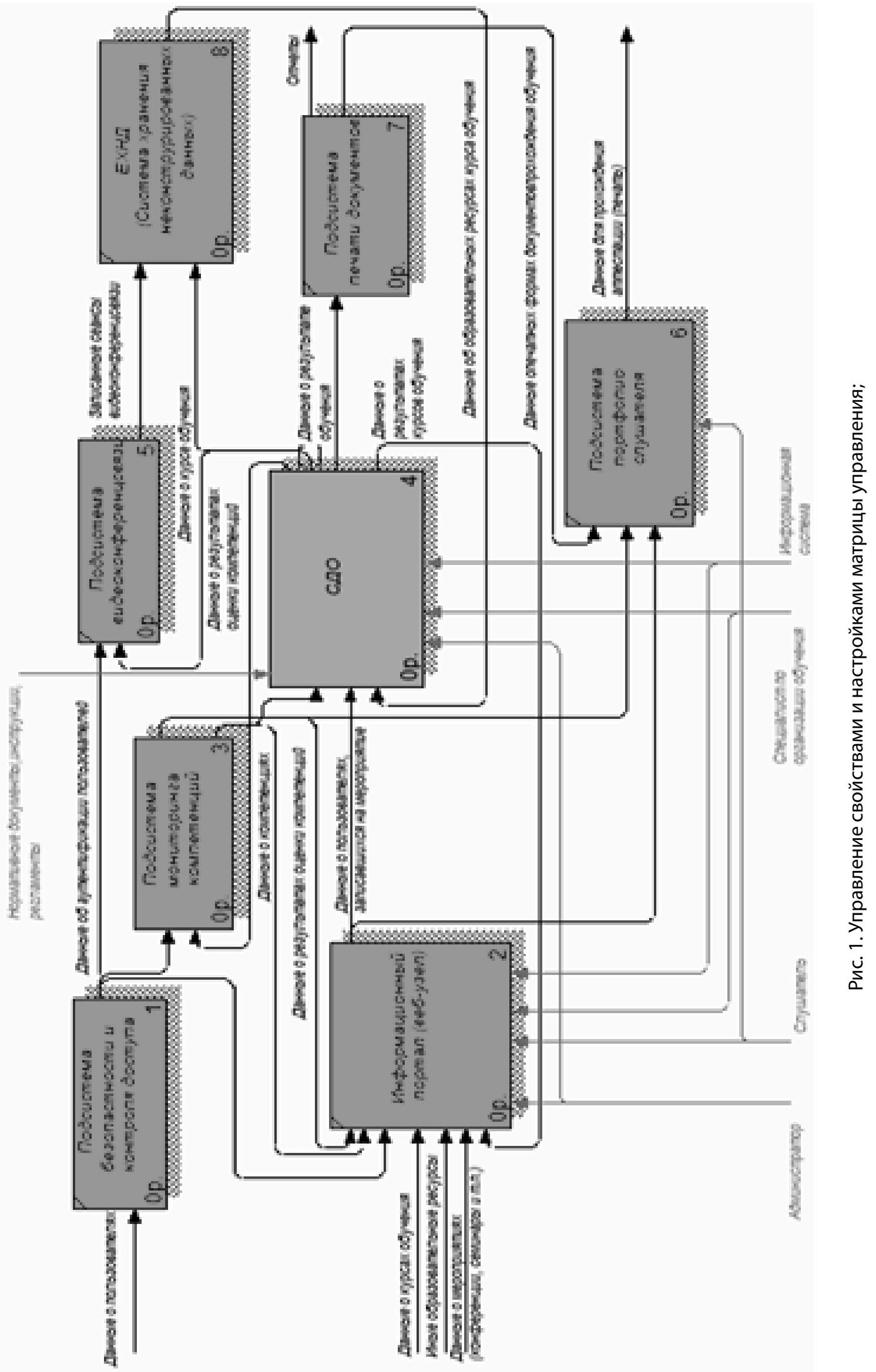




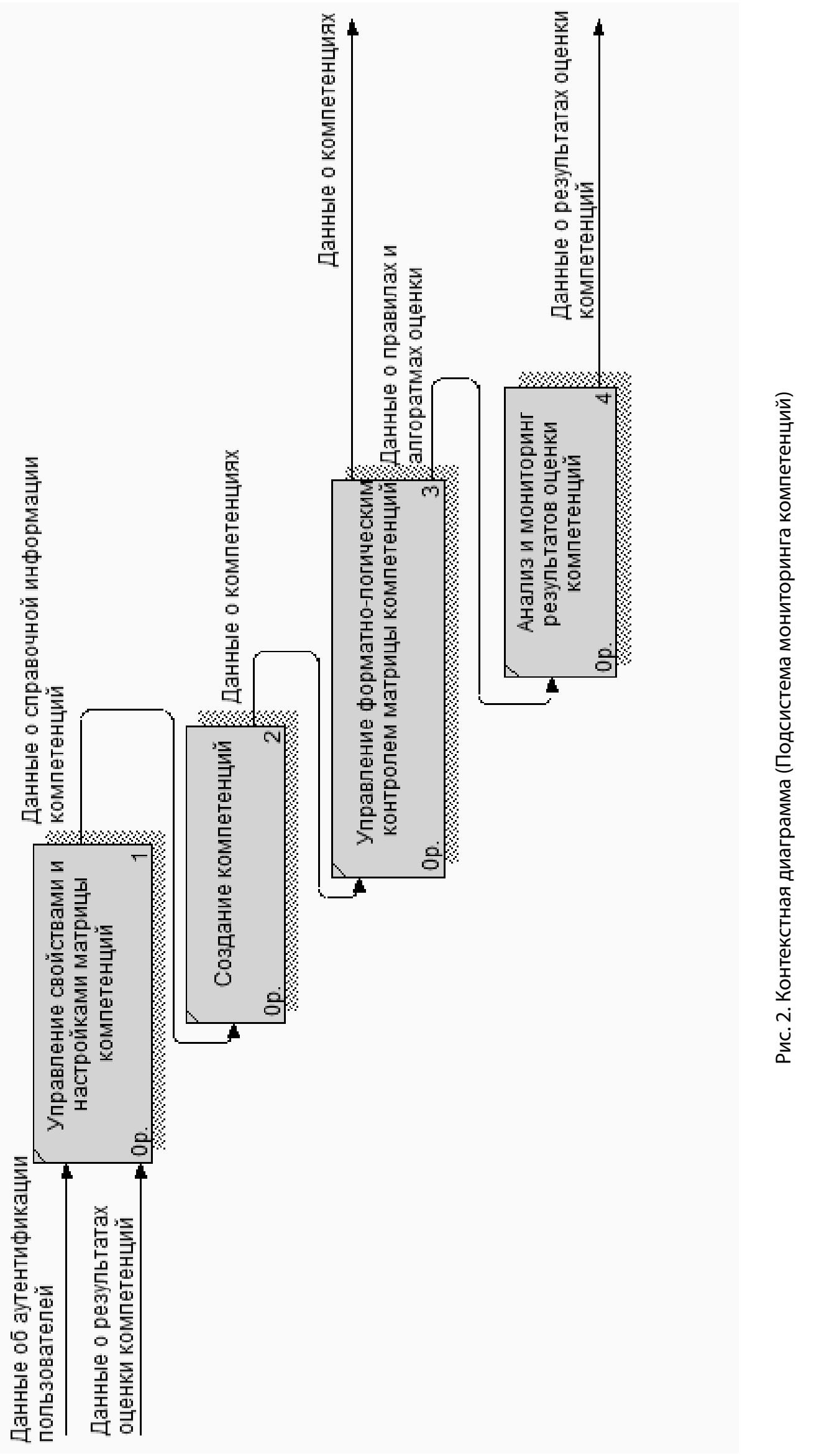




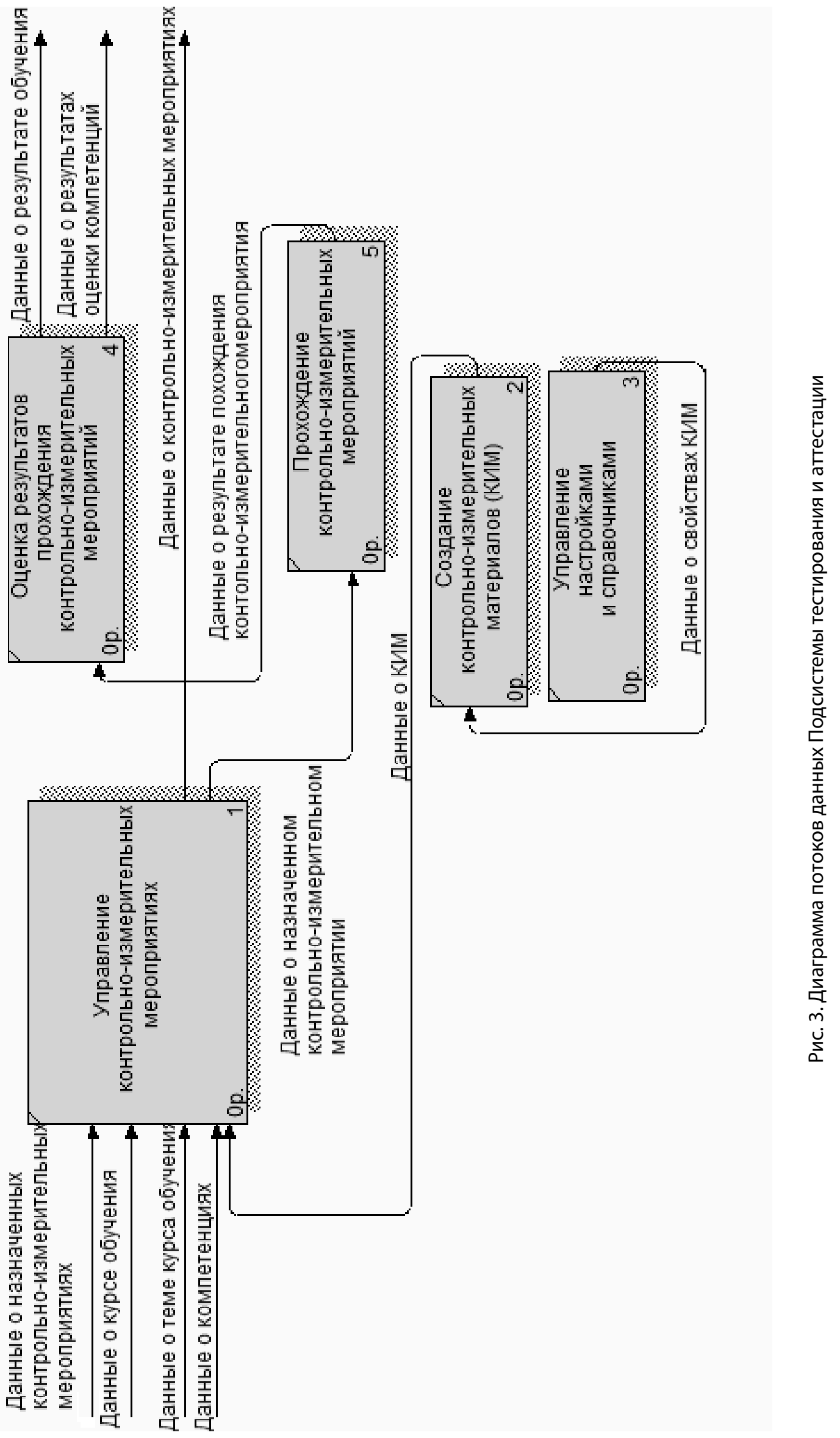


предоставления возможностей организации индивидуальной образовательной траектории в течение всей жизни;

- укрепление, объединение образовательных ресурсов общества

- формирование образовательного социального партнерства как компонента гражданского общества.

Непрерывное, в частности, профессиональное образование способствует формированию профессиональной основы кадрового потенциала, формированию социально адаптированной части лиц, получающих образование последовательно на каждом этапе профессионального развития.

Создание автоматизированной информационной среды непрерывного образования (далее - АИС НО) позволит организовать единое окно доступа к курсам профессионального образования различных образовательных организаций и иных структур, осуществлять поддержку образовательного процесса с использованием электронных дистанционных технологий, осуществлять мониторинг компетентностей и рекомендаций по их развитию, а также осуществлять автоматизированный сбор результатов обучения и участия в мероприятиях дополнительного образования, формировать подтверждающие документы об успешности прохождения модулей, курсов обучения [3-6].

По результатам анализа бизнес-процессов организации, а также формируемых потоков данных, была создана функциональная модель АИС НО, представленная на рисунке 1.
Одной из подсистем АИС НО является подсистема мониторинга компетенций (рисунок 2). Функциональными возможностями подсистемы является формирование и описание компетенций, настройка матрицы компетенций и выполнение алгоритма определения результатов анализа компетенций.

Подсистема мониторинга компетенций, может быть декомпозирована на функциональные модули:

- Управление свойствами и настройками матрицы управления;

- Создание компетенций;

- Управление форматно-логическим контролем матрицы компетенций;

- Анализ и мониторинг результатов оценки компетенций.

Анализ и мониторинг результатов оценки компетенций выполняется с помощью подсистемы тестирования и аттестации, где по итогам полученных результатов формируется перечень компетенций пользователя, и даются рекомендации по их усовершенствованию. Рекомендации формируются на основании анализа профессиональной деятельности пользователя [7-9], данные о которой содержатся в личном профиле пользователя. На рисунке 3 представлена диаграмма потоков данных Подсистемы тестирования и аттестации.

По результатам детализации диаграмм и декомпозиции каждой подсистемы, были выявлены основные требования к системе поддержки непрерывного образовательного процесса [10].

\section{ЛИТЕРАТУРА}

1. Пережовская А. Н. Непрерывное образование: цели, задачи, содержание, функции, перспективы развития [Текст] // Проблемы и перспективы развития образования: материалы VI Междунар. науч. конф. (г. Пермь, апрель 2015 г.).—- Пермь: Меркурий, 2015.—C. 38-41.—URL https://moluch.ru/conf/ped/ archive/149/7617/ (дата обращения: 09.03.2020).

2. Gorelov G.V., Romashkova 0. N. Influence of russian, spanish and vietnamese speech characteristics on digital information transmission quality // IEEE International Symposium on Industrial Electronics Proceedings of the IEEE International Symposium on Industrial Electronics, ISIE'96. Part 1 (of 2). sponsors: IEEE, Warsaw University of Technology. Warsaw, Poland, 1996, p.311-313.

3. Bobrikova E., Gaidamaka Y., Romashkova 0. The application of a fluid-based model for the analysis of the distribution time of a file among users in peer-to-peer network // Selected Papers of the II International Scientific Conference "Convergent Cognitive Information Technologies" (Convergent 2017). CEUR Workshop Proceedings, Volume 2064. p. 55-61. Available at: http://ceur-ws.org/Vol-2064/paper06.pdf

4. Gudkova, I.A., Romashkova, 0.N., Samoylov, V. E. Determination of the range of the guaranteed radio communication in wireless telecommunication networks of IEEE802.11 standard with the use of ping program // B сборнике: CEUR Workshop Proceedings 8. Cep. "ITTMM 2018 - Proceedings of the Selected Papers of the 8th International Conference "Information and Telecommunication Technologies and Mathematical Modeling of High-Tech Systems'"' 2018. C. 54-59.

5. Gaidamaka, Y.V., Romashkova, O.N., Ponomareva, L.A., Vasilyuk, I. P. Application of information technology for the analysis of the rating of university // B cборнике: CEUR Workshop Proceedings 8. Cep. "ITTMM 2018 — Proceedings of the Selected Papers of the 8th International Conference "Information and Telecommunication Technologies and Mathematical Modeling of High-Tech Systems'"' 2018. C. 46-53.

6. Gorelov G.V., Kazanskii N. A., Lukova 0. N. Communication quality assessment in speech packet transmission networks with random service interrupts // Automatic Control and Computer Sciences. 1993., vol.27., no.1., p.62. 
7. Пономарева Л.А., Ромашкова 0. Н., Василюк И. П. Алгоритм оценки эффективности работы кафедр университета для управления его рейтинговыми показателями // Вестник Рязанского государственного радиотехнического университета. 2018. № 64. С. 102-108.

8. Ромашкова 0.Н., Пономарева Л. А., Василюк И. П. Линейное ранжирование показателей оценки деятельности вуза // Современные информационные технологии и ИТ-образование. 2018. Т. 14. № 1. С. 245-255.

9. Romashkova 0.N., Pavlicheva E. N. Resource Management In Distance And Mobile Education Systems// B сборнике: CEUR Workshop Proceedings 9. Cep. "Selected Papers of the Proceedings of the 9th International Conference Information and Telecommunication Technologies and Mathematical Modeling of High-Tech Systems, ITTMM 2019" 2019. C. 102-108.

10. Ромашкова 0.Н., Орехова Е. В. Единая образовательная информационная среда организации и поддержки открытого и непрерывного образования // Вестник Российского университета дружбы народов. Серия: Информатизация образования. 2016. № 1. С. 128-134.

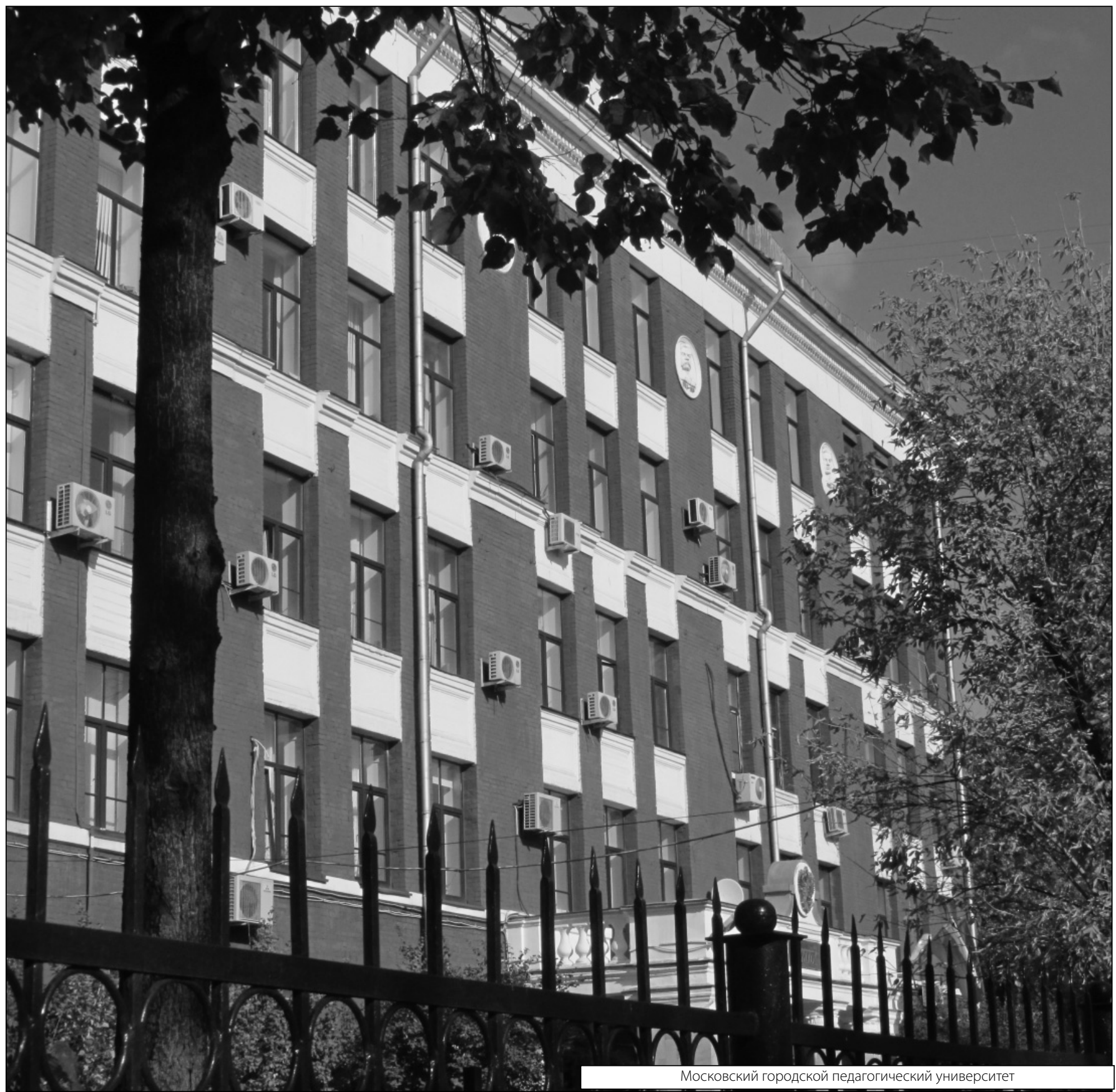

